\title{
Os Estudos Coreológicos como Práxis para Construção de uma Dramaturgia Afetiva
}

\author{
Melina Scialom \\ Universidade Estadual de Campinas - UNICAMP, Campinas/SP, Brasil \\ E-mail: melinascialom@gmail.com
}

\section{Resumo}

O presente artigo traz os Estudos Coreológicos como uma práxis que, ao ser apre(e)ndida pelo bailarino/ator/performer, permite que esse desenvolva um domínio do seu movimento, empoderando-se de sua potência criativa na composição em dança. A Coreologia, quando incorporada, ativa um processo de pensar em termos de movimento - um tipo de pensamento que advogo como dramatúrgico. Para experimentar a dramaturgia que surge do pensamento ocorrido por meio do movimento, trabalhamos com uma obra do pintor Wassily Kandinsky, como um mapa de intensidades, formas, dinâmicas e espacialidades que orientaram a criação dos performers. O processo criativo resultante dessa experimentação revelou uma dramaturgia afetiva, realizada pelos intérpretes-criadores do trabalho que coletivamente organizaram afetos - individuais e coletivos - no espaço-tempo da cena.

Estudos Coreológicos. Dramaturgia. Afeto.

Processo de Criação.
The present article introduces the Choreological Studies as a praxis that, when (a)prehended by the dancer/actor/performer, allows the development of a mastery of movement, empowering him or herself of its creative power in dance making. When embodied, Choreology activates a process of thinking through movement, a type of thinking that I advocate as dramaturgical. To experiment the dramaturgy that emerges from the thinking that happens through movement, we worked with a painting from Wassily Kandinsky as a map of intensities, shapes, dynamics and spatialities that guided the creation of the performers. The resulting creative process of this experimentation revealed an affective dramaturgy, done by the interpreters-creators of the work who, together, organized the affects - individual and collective - in the space-time of the scene.

Choreological Studies. Dramaturgy. Affect.
Creative Process. 
Ao longo de minha trajetória, enquanto artista-pesquisadora, venho me aprofundando em diferentes abordagens sobre a práxis de Rudolf Laban, sob a orientação de mestras, cuja diversidade de perspectivas influenciaram diferentes desenvolvimentos na Arte do Movimento. Foram elas (em ordem cronológica): Joana Lopes - que me introduziu ao pensamento labaniano sob a perspectiva teatral, da Arte do Movimento de Maria Duschenes e política de Eugênica Cassini Ropa; Ciane Fernandes - que me introduziu à Laban Movement Analysis; Peggy Hackney - com quem me aprofundei nos Bartenieff Fundamentals; Vivian Bridson - que me acordou para a corporeidade e expressividade da dança-teatro; Carol-Lynne Moore - que me acordou para os detalhes do conhecimento produzido por Laban. Além delas, cito também os Estudos Coreológicos - através da Especialização em Estudos Coreológicos, em que Laban se torna um viés para criar e pensar a dança quando fui aluna de Valerie Preston-Dunlop, Rosemary Brandt, Alisson Curtis-Jones e Melanie Clarke.

$O$ treinamento recebido na diversidade de perspectivas da práxis de Laban me permitiu entender a Arte do Movimento enquanto uma série de princípios que operam sobre o corpo, tanto em estado cênico quanto cotidiano. Isso me possibilitou incorporar maneiras de se olhar, trabalhar e me expressar através do soma, sendo um marco na forma com que elaboro e realizo minhas pesquisas e como ensino dança e expressão corporal. A variedade de perspectivas que compõem meu conhecimento sobre a práxis de Laban influencia também meu pensamento dramatúrgico - como performer e orientadora artística. É importante entender primeiramente o que é a práxis coreológica, para depois mergulhar em como venho desenvolvendo um pensamento dramatúrgico relacionado à criação em dança.
Os Estudos Coreológicos (EC) são um dos braços da práxis de Laban organizados por sua pupila Valerie Preston-Dunlop junto aos seus diversos colaboradores - artistas, docentes e pesquisadores do antigo Centro Laban (Laban Centre) no Reino Unido (atualmente chamado de Trinity Laban Conservatoire of Music and Dance). Pelo fato de este trabalho não se tratar de uma revisão sobre as bases metodológicas e teóricas dos EC, vou me limitar em apontar somente os princípios básicos da práxis que interessam ao desenvolvimento do artigo.

Os EC são considerados por Preston-Dunlop e Sanchez Colberg (2010) como um dos desdobramentos da filosofia de Laban focado especificamente sobre o universo da dança e do fazer artístico das artes corporais. Em sua tese de doutorado publicada em 1981, Preston-Dunlop (1981) define os EC a partir de quatro modos de investigação, os quais envolvem: os estudos que acentuam a experiência de dançar; aqueles que promovem a investigação do material gerado através da dança; o desenvolvimento de métodos analíticos; e, por fim, a promoção de formas de documentação da dança. Dois marcos teóricos dos EC foram as publicações dos livros Dance is a Language, isn't it? (PRESTON-DUNLOP, 1980) e Dance and the Performative (PRESTON-DUNLOP; SANCHEZ-COLBERG, 2010), cuja primeira edição foi publicada em 2002. Na primeira publicação, Preston-Dunlop apresenta uma consideração sobre a dança enquanto meio de expressão corporal, incluindo os cinco elementos estruturais (ou categorias) que compõem o movimento dançado: Corpo, Espaço, Dinâmicas, Ação e Relacionamentos.

Já na segunda, há uma discussão mais aprofundada sobre as bases teóricas que fundamentam os EC (como a semiótica, a fenomenologia, a filosofia da dança, a comunicação não verbal, a psicologia e as teorias da comunicação). Ao mesmo tempo, também há um distanciamento para olhar a dança como uma composição que acontece através do entrelace (não padronizado) entre quatro fios/fi- 
bras (strands): o performer (bailarino, ator ou aquele que está em cena se apresentando), o movimento, o som e o espaço. Estas fibras se articulam estabelecendo nexos entre elas, de acordo com as necessidades de cada criação. Para trabalhar com a criação em si é estabelecida uma perspectiva triádica que inclui o fazer, o performar (apresentar/dançar) e a apreciação (o compartilhamento com o público).

A perspectiva coreológica é proposta por Preston-Dunlop como uma forma de conhecimento na dança, estando relacionada ao entendimento de como o movimento acontece, opera e funciona artisticamente - no corpo do dançarino (performer), coreograficamente (composição) e no como a obra é recebida pelo público (espectador). Ela também envolve a pesquisa sobre os elementos estruturais do movimento e em como lidar e manipular estes elementos na criação em artes cênicas. Estes são, também, a base para a pesquisa em dança, a qual está relacionada aos parâmetros e às lentes que guiam a observação e o uso da materialidade da dança como um meio expressivo de criação e educação artística.

Da mesma forma que Laban tinha o projeto de encontrar os elementos básicos que compõem o movimento expressivo humano, a perspectiva coreológica visa desenvolver parâmetros, estruturas e lentes para guiar a observação do movimento e a criação em dança na contemporaneidade. Tem também o objetivo de alimentar a habilidade do performer em aproveitar os recursos provindos desses parâmetros e estruturas para uso de forma criativa, contribuindo para o desenvolvimento do olhar crítico do dançarino, transformando-o em um bailarino-pesquisador que opera através da prática1.

Os EC são um desdobrar da práxis labaniana, pois, em contraponto à Laban, que dialogou com teorias modernas e emergentes na primeira metade do século XX, ele propõe diálogos com pensamentos

1 As práticas labanianas como originárias de uma metodologia de prática como pesquisa foram discutidas por Fernandes et.al. (2019), que mostram como o pensamento de Laban no início do século $X X$ já era intrinsecamente comprometido a uma pesquisa que acontece através do movimento e do fazer da dança. nas áreas da filosofia, da comunicação e das artes em ascensão na segunda metade do século, como a linguística, a semiótica e a fenomenologia. Tão essencial quanto o pensamento teórico-filosófico que ampara a Coreologia, é o fato de que ela precisa ser experienciada pelo performer para ser compreendida e acionada, assim como a práxis de Laban como um todo.

O entendimento corporal (e a realização física) de todos os elementos estruturantes é o que torna a Coreologia um conhecimento daquele que dança, atua e se move criativamente em cena. Assim, é a partir dessa premissa da experiência e da ferramenta metodológica que associei a Coreologia à dramaturgia para investigar maneiras do performer-criador ${ }^{2}$ se tornar responsável pela dramaturgia de seu trabalho criativo.

\section{Laboratórios de Coreologia e pensar em movimento}

O estudo (incorporado) da Coreologia aqui relatado foi realizado através de laboratórios de pesquisa efetivados em encontros semanais com duração de três horas no estúdio, onde trabalhei durante dois anos (2017 e 2018) com artistas da cena, alunos de graduação (em dança e teatro) e de pós-graduação, com médio, pouco ou nenhum conhecimento da práxis de Laban. Venho trabalhando com a metodologia de laboratórios desde 2008 em sessões de investigação as quais têm o movimento expressivo como linguagem que processa informações e formula perguntas de pesquisa (SCIALOM, no prelo). Inclusive, esta foi a primeira vez em que trabalhei em laboratório junto com um grupo de voluntários (ao invés de estar sozinha, como nas experiências anteriores).

Nestes encontros, fui desenvolvendo formas de trabalhar as cinco categorias dos EC - Dinâmica, Espaço, Corpo, Ação e Relacionamento - de forma a associar pensamento e consciência afetiva ao mo-

\footnotetext{
2 Ao longo deste artigo, utilizo-me da palavra performer para me referir ao artista da cena, seja ator, dançarino ou atuante. $\mathrm{O}$ uso desta palavra segue em acordo com a terminologia dos EC.
} 
vimento, e vice e versa, em sessões práticas de movimento expressivo. Estas aconteceram a partir de improvisações sobre os elementos pertencentes a cada uma das cinco categorias. Por exemplo, para trabalhar com a categoria Espaço e desenvolver nos performers o que Longstaff (1996, p. 65) chama de "conhecimento espacial", desenvolvi exercícios para aprimorar o uso do volume que está ao redor do corpo e de modelar a cinesfera individual de cada um. Estes envolviam o emprego das escalas de movimento elaboradas por Laban (LABAN, 1966) em repetições continuadas até estarem incorporadas de forma que o corpo passasse a conhecer o caminho e o esforço (qualidade de movimento) necessários para traçar conexões entre os pontos que formam os vértices dos sólidos platônicos - em especial, o octaedro, o cubo e o icosaedro (sólidos mais utilizados por Laban para estruturar suas escalas). A realização das escalas permitiu a exploração dos princípios da Harmonia Espacial ${ }^{3}$ como oposição harmônica, a tensão espacial e o sequenciamento, além das leis - do equilíbrio (alternando entre estabilidade e labilidade, equilíbrio e desequilíbrio); a lei do fluir a partir do centro (movimento que é iniciado por qualquer parte do corpo sempre passa pelo centro ou o afeta de alguma forma), e a lei do contra-movimento (todo movimento em qualquer direção sempre possui um duplo estabilizador).

A repetição continuada de uma escala permitiu que a musculatura e o sistema háptico ${ }^{4}$ fossem

3 Laban usa do termo Harmonia Espacial (space harmony) como sinônimo de Corêutica (Choreutics) no intuito de associar sua práxis relacionada ao espaço às estruturas e simbologias que existem na harmonia musical. Em seu livro Choreutics, Laban (1966) se refere repetidamente à busca por um movimento harmonioso em oposição à movimentação limitada e atravancada. De forma análoga às escalas musicais, Laban criou as escalas de movimento, baseadas nas leis da harmonia musical, procurando uma forma de se criar exercícios corporais que fossem análogos aos exercícios de harmonia realizados por um músico.

4 O sistema háptico, segundo Longstaff (1996), está relacionado ao desenvolvimento de uma consciência corporal vinda das orientações que o corpo recebe de seus sistemas tátil, vestibular e sensório-motor cinestésico, sempre em relação à força gravitacional que opera sobre o corpo. aprendendo sobre o acesso à determinadas localizações do mapa cinesférico pessoal, como sugere a estudiosa de Laban, Carol-Lynne Moore (2009). Assim, é somente através da experiência que conseguimos apre(e)nder uma escala, ou os percursos que o corpo percorre pela geografia disponível ao redor de seu corpo, para podermos utilizar deles numa expressão particular. Por exemplo, considerando a escala de defesa ou dimensional ou do balanço (swing), que tem os seis vértices do octaedro como um mapa para a construção da cinesfera, após aprendermos ${ }^{5}$ sobre a localização na cinesfera dos seis pontos (vértices do octaedro que se forma ao redor do corpo), iniciamos um sequenciamento que direcionava o movimento de um ponto até o outro ciclicamente. Repetimos a sequência, ou a escala, durante pelo menos cinco minutos sem parar, com acompanhamentos sonoros diversos. Laban explica que nesta escala:

o balanço pendular constante até estas direções [cima, baixo, direita, esquerda, frente e trás] vai vagarosamente educando o corpo para um sentimento espacial mais exato, por exemplo, a escala do balanço vai dar uma base por onde o conhecimento das complicações e combinações de direções espaciais pode ser construído (LABAN apud MALETIC, 1987, p. 67) ${ }^{6}$.

Acrescentando que, segundo Maletic (1987), Laban advogava pelo exercício das escalas para, não somente desenvolver a conscientização do movimento, mas também a força muscular do dançarino. Então, após diversas repetições e já tendo cartografado a cinesfera com que estávamos trabalhando (octaedro), começamos a improvisar so-

5 Ao longo deste artigo, utilizo-me da primeira pessoa do plural para indicar que, mesmo tendo a posição de líder, ao longo dos laboratórios, estive praticando junto com os participantes a fim de todos nós experienciarmos a incorporação da práxis coreológica.

6 Traduzido livremente pela autora do original: "The constant pendular swinging into these directions will slowly educate the body to a more exact spatial feeling, i.e., the swing scale will give a foundation from which knowledge of the complications and combinations of spatial directions can be built up". 
bre o mapa. Nesse momento, eu chamava atenção especial para que os participantes explorassem o mapa, não considerando-o como uma restrição, mas, sim, investigando toda sua potencialidade, levando a atenção para como o fluxo do corpo no espaço estava afetando-os, incluindo as imagens (tidas por cada participante) que surgiam dos deslocamentos.

Outra experiência, ainda trabalhando com a Harmonia Espacial, foi a investigação dos ritmos espaciais (spatial rhythms). Para entender este termo, primeiramente, é preciso lembrar que, para Laban, o conjunto de traços resultantes (desenho) que o movimento faz no espaço (trace-forms) podem ser vistos como unidades métricas-rítmicas dispostas tridimensionalmente (LABAN, 1966). Assim, para ele, o movimento tem qualidades rítmicas espaciais e temporais que são coloridas pela energia com que acontecem: "movimento é relativo ao deslocamento espacial que acontece em um ritmo temporal particular com uma força muscular bem específica"7 (MCCAW, 2011, p. 86). Voltando para o exemplo da escala de movimento descrita acima, quando uma movimentação resulta em um conjunto de desenhos espaciais ela cria um ritmo espacial. Laban associava os ritmos espaciais criados pelo corpo em deslocamento a um pensamento cosmológico de que o corpo está em fluxo junto ao cosmos e à natureza. Tal ideia está explícita em toda a associação que ele faz da Harmonia Espacial com a geometria sagrada, por exemplo (LABAN, 1966).

Para incorporar ritmos espaciais e improvisar com os participantes, partimos das escalas que nós vínhamos praticando, como a escala $\mathbf{A}^{8}$. Após di-

7 Traduzido livremente pela autora do original: "movement is concerned with spatial displacement which are carried out in a particular temporal rhythm with a very specific muscular force".

8 A escala A é talvez a escala de movimento que acontece na geografia do icosaedro mais conhecida e trabalhada por labanianos. Ela consiste em traçar linhas transversas (nem centrais passando pelo centro e nem periféricas passando pela borda) entre os vértices da forma cristalina, sequenciando repetidamente pontos nos três planos - horizontal, vertical e sagital -, até que todos os pontos tenham sido acessados, ciclicamente.

versas semanas praticando a escala, durante as improvisações livres, começamos a experimentar a desconstrução do sequenciamento original de forma a cortar, colar, repetir, pausar e ocultar partes. Esta desconstrução, sugerida pela práxis coreológica, começou a criar diferentes ritmos espaciais e também a nos trazer determinadas sensações, particulares a cada ritmo espacial criado.

No final de cada sessão, compartilhávamos com o grupo alguns trechos significativos que selecionávamos de nossa movimentação. Comentávamos, tanto sobre a experiência (afetos e imagens) de quem se movia, quanto do como quem via (potencial público e no caso os próprios participantes do grupo que assistiam uns aos outros) era afetado pelo movimento exposto. Ao longo dos encontros, fui desenvolvendo esta metodologia na realização de outras escalas a fim de que o performer, com um conhecimento espacial incorporado, começasse a pensar em termos de movimento: não através de palavras, significados e simbologias, mas através das suas sensações ao traçar e materializar cinesferas ${ }^{9}$.

Ao trabalhar com a experiência do corpo, utilizo-me da teoria dos afetos para fundamentar o trabalho aqui discutido e articular as vivências corporais de forma não-representacional, ou seja, a nível pré-simbólico. A teoria dos afetos surgiu na filosofia de Baruch Spinoza no século XXVII, foi posteriormente elaborada no século XX e XXI por Deleuze e Guattari (2017) e profundamente articulada na contemporaneidade pelo filósofo Brian Massumi (2015). Massumi explica que Spinoza definiu o afeto como o poder de afetar e ser afetado. Porém, apesar de Spinoza ter associado o afeto com emoção, a filósofa contemporânea Erin Manning (2007, p. xxi) lembra que afeto não é emoção, e sim um tipo de movimento

\footnotetext{
9 Gostaria de apontar que este exemplo é somente um entre diversos outros realizados sobre as categorias dos EC. Ao longo dos dois anos de laboratório foi possível explorar com detalhes todas as cinco categorias dos EC e, da mesma forma com que exemplifiquei na categoria Harmonia Espacial, desdobrar o potencial expressivo, cinestésico e coreográfico de cada uma.
} 
- um "estando do movimento do mundo"10, sendo a primeira coisa que se sente quando há uma relação.

Já, para a teórica da dança Dee Reynolds (2012), afeto é incorporado e precede todos os tipos de ações cognitivas que rotulam as emoções que sentimos em categorias reconhecíveis ou simbólicas. A autora explica que, na dança, o afeto pode tanto acontecer no bailarino que se move através das sensações e experiências corporais geradas (corpo afetado), quanto também no público, quando, através da empatia cinestésica (kinesthetic empathy), processa o movimento do outro (corpo que afeta) em seu próprio corpo, tornando-se assim matéria da experiência. A teoria dos afetos, portanto, diz respeito às intensidades que são geradas intra e inter corporalmente, e que existem antes de serem representadas semioticamente.

Associar a presente investigação à teoria dos afetos sugere que aquilo que nos interessa está na esfera da experiência corporal e não do que ela representa simbolicamente ou conceitualmente, incluindo a capacidade do corpo de afetar e ser afetado. O corpo deve se tornar sensível para as experiências geradas a partir de diferentes combinações de movimento e saber articular estas combinações para gerar novas intensidades seria um tipo de pensar afetivamente.

A associação entre pensamento e movimento acontece ao se atentar (durante o próprio movimento) à expressividade gerada (simbólica ou não) quando o corpo se move. Junto com a dinâmica corporal acontece uma atenção sobre a corporeidade e sobre os resultados afetivos desta, tanto para aquele que se move (e é afetado pelo movimento), quanto para aquele que vê (está em relação) e compartilha do afeto através de sua presença. Ao focar sobre a experiência relacionada ao domínio do movimento (ter consciência e controle voluntário da dinâmica corporal), percebemos que não é somente a "mente" que pensa, mas a integração corpo-mente ou o soma ${ }^{11}$.

10 Livre tradução da autora do original: "with-ness of the movement of the world".

$11 \mathrm{Na}$ epistemologia somática já é amplamente discutido como o corpo é a integração entre corpo e mente e que,
Sem o movimento o pensamento se tornaria uma conceituação mental, sendo o oposto do que estou propondo. Dessa maneira, introduzo um processo de "pensar em movimento", que acontece justamente no ato (presente) em que o individuo se movimenta em uma integração somática com a experiência vivida. Laban (1978) já trabalhava sobre este conceito (movement thinking) ao estruturar sua Arte do Movimento. Grande parte de seu trabalho, inclusive, foi elaborado visando entender, decupar e racionalizar os processos corporais para trabalhar sobre eles, manipulando-os de acordo com as necessidades expressivas de cada um (artista). Tanto sua Corêutica (Harmonia Espacial) quanto Eucinética estavam pautados sobre formas (exercícios) para o desenvolvimento de um pensamento que acontece através do movimento (o que Laban chamou de thinking in terms of movement). Portanto, ao associar Laban às discussões contemporâneas de dramaturgia na dança, encontrei as conexões possíveis entre dramaturgia, Coreologia e o trabalho do performer/ator/dançarino, como discutirei mais adiante.

Com o passar dos encontros e meses de pesquisa, os laboratórios foram evoluindo para uma prática sistemática dos EC, explorando as outras categorias citadas acima. Para experimentar as possibilidades criativas do pensar em movimento associado aos afetos que sentíamos, tanto através de nossos movimentos quanto dos movimentos vindo dos outros corpos, realizamos um processo criativo de um trabalho de dança que chamamos de Kandinsky.

\section{Kandinsky e a dramaturgia afetiva}

Apesar de este trabalho se utilizar dos EC como fundamento para se pensar em movimento, ele contrapõe o tratado de Preston-Dunlop (1980), que propõe que a dança seja estruturada para dar ou gerar

enquanto matéria integrada, pensa. Inclusive, Bonnie B. Cohen (2015), aluna de Bartenieff (pupila de Laban) e fundadora do Body Mind Centering, defende que cada um dos sistemas que integram nosso corpo tem um tipo de pensamento específico. 
sentido. Isso porque, na busca por abandonar os sentidos gerados pelo movimento, procuramos nos manter em um estado de pura experiência a nível pré-simbólico, cujo interesse é olhar para aquilo que vem antes do sentido ser elaborado pela mente - o afeto gerado pelo indivíduo que se movimenta/dança.

Assim, ao invés de elaborar um trabalho a partir do entendimento da dança enquanto linguagem que produz sentido e pode ser analisada sintaxicamente enquanto tal, como defendido por Preston-Dunlop, eu proponho uma dança que seja uma manifestação afetiva e opere em outro nível de transmissão de intensidades: o da empatia e cinestesia. Esta proposta não é uma busca por estabelecer verdades, mas, sim, a procura pelo que pode o movimento e como organizar esse tipo de experiência em composições dançadas. Desse modo, nasceu a obra e experimentação Kandinsky ${ }^{12}$.

Propus para o grupo de performers participantes dos laboratórios trabalharmos com os afetos gerados a partir de uma imagem visual compartilhada. Juntos escolhemos a pintura chamada Composição $n .2$ do artista Wassily Kandinsky. A própria história de relação entre Kandinsky e Laban (PRESTON-DUNLOP, 1994) foi um dos fatores que influenciaram a escolha da obra deste artista. Os dois artistas foram contemporâneos e se conheceram em Munique, na Alemanha, no início do século $X X$, onde Laban chegou a ter aulas de artes com Kandinsky (DÖRR, 2008). Ambos produziram tratados sobre suas artes, associando-as à espiritualidade. Kandinsky acreditava que os elementos primordiais de sua pintura eram as cores e as formas. Estas são análogas às noções que Laban trazia de qualidade de movimento e forma (shape). A maneira como Kandinsky via a harmonia entre as cores como vibrações pode ser diretamente relacionada à Eucinética de Laban. Consideramos, portanto, que utilizar uma obra de Kandinsky como um mapa para trabalhar com conhecimento labaniano incorporado seria uma escolha coerente.

12 Participaram dessa criação Isabela Berto, Guilherme Martins, Caroline Sobolewska, Elisa Abrão, Ana Flávia Felice, Verônica Fabrini e Melina Scialom.
Figura1 - Dançarinos durante ensaio-aberto de Kandinsky.

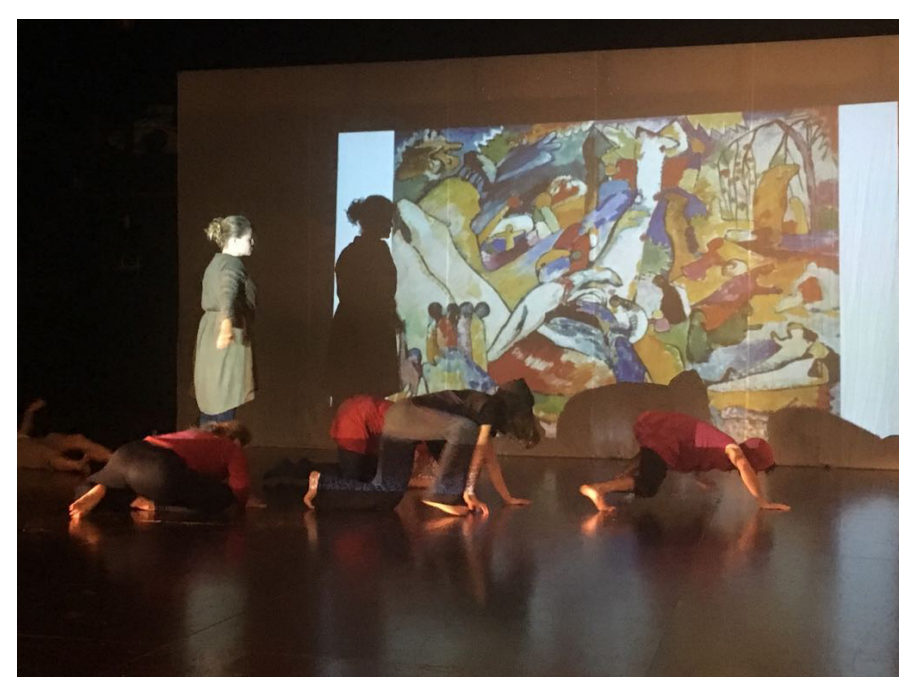

Fonte: Foto de Sabrine Schultz.

Após a escolha da obra, projetamos a imagem da pintura na parede do estúdio e conversamos sobre o que nos chamava atenção, incluindo cores, intensidades, densidades, traços, formatos, formas, combinações, disposição das linhas, etc. Propus que os participantes utilizassem a pintura como um mapa ou partitura e que acessassem seus conhecimentos labanianos (incorporados) para traduzir as cores, formas, ritmos espaciais e afetos para seus corpos e movimentos, ou seja, em dinâmicas/formas/ ações/relacionamentos corporais. A partir desta indicação, iniciamos sessões de experimentação em que a imagem da Composição n. 2 era projetada na parede da sala, enquanto os performers improvisavam e vivenciavam processos de pensar em movimento, em conjunto, compartilhando o espaço e se relacionando quando sentissem necessidade. Estas improvisações tinham duração entre 20 e 30 minutos.

Após cada sessão, nos reuníamos em uma roda de conversa e comentávamos sobre nossa experiência naquela improvisação. Sugeri aos participantes que, a cada sessão, revisitassem os elementos da imagem, os movimentos e as relações (com o grupo) que o afetaram, sempre percebendo as mudanças (dos movimentos e dos afetos 
gerados), como também as experiências que se repetiam. Diferente de uma improvisação cujo movimento que emerge dos indivíduos deve ser original, instantâneo e de natureza experimental (como descreve BARDET, 2016 e ELIAS, 2015), proponho que o ato de improvisar, neste tipo de criação, seja sempre uma re-criação do mapa afetivo, onde, no caso deste exercício específico, vem de uma partitura pictórica (Composição n. 2, de Kandinsky).

Nas conversas sobre nossas experiências pessoais depois de cada sessão, nos utilizávamos da linguagem incorporada dos EC para incentivar que a própria percepção do que acontecia - do corpo se movendo no tempo e espaço e em relação a outros corpos - fosse sempre consciente e, portanto, reproduzível (no sentido de re-vivienciado e não copiado). Nestas conversas, ao ver os performers articulando suas experiências em um vocabulário de movimento labaniano (ao invés de uso de metáforas pessoais), percebi que a incorporação da práxis de Laban atua como uma espécie de saber empírico, no sentido elucidado por Marcel Mauss (1973).

Nesse contexto, a práxis de Laban se torna a ponte unificadora entre a expressão linguística verbal e o conhecimento corporal intrínseco ao movimento. Ela se torna também uma via de acesso direta aos afetos experienciados pelo corpo. Ela facilita uma maneira específica de pensar-mover menos subjetiva e metafórica e mais objetiva, permitindo, assim, que cada indivíduo pudesse integrar a sua própria individualidade na expressão do outro.
Figuras 2 e 3 - Dançarinos durante ensaio-aberto de Kandinsky.
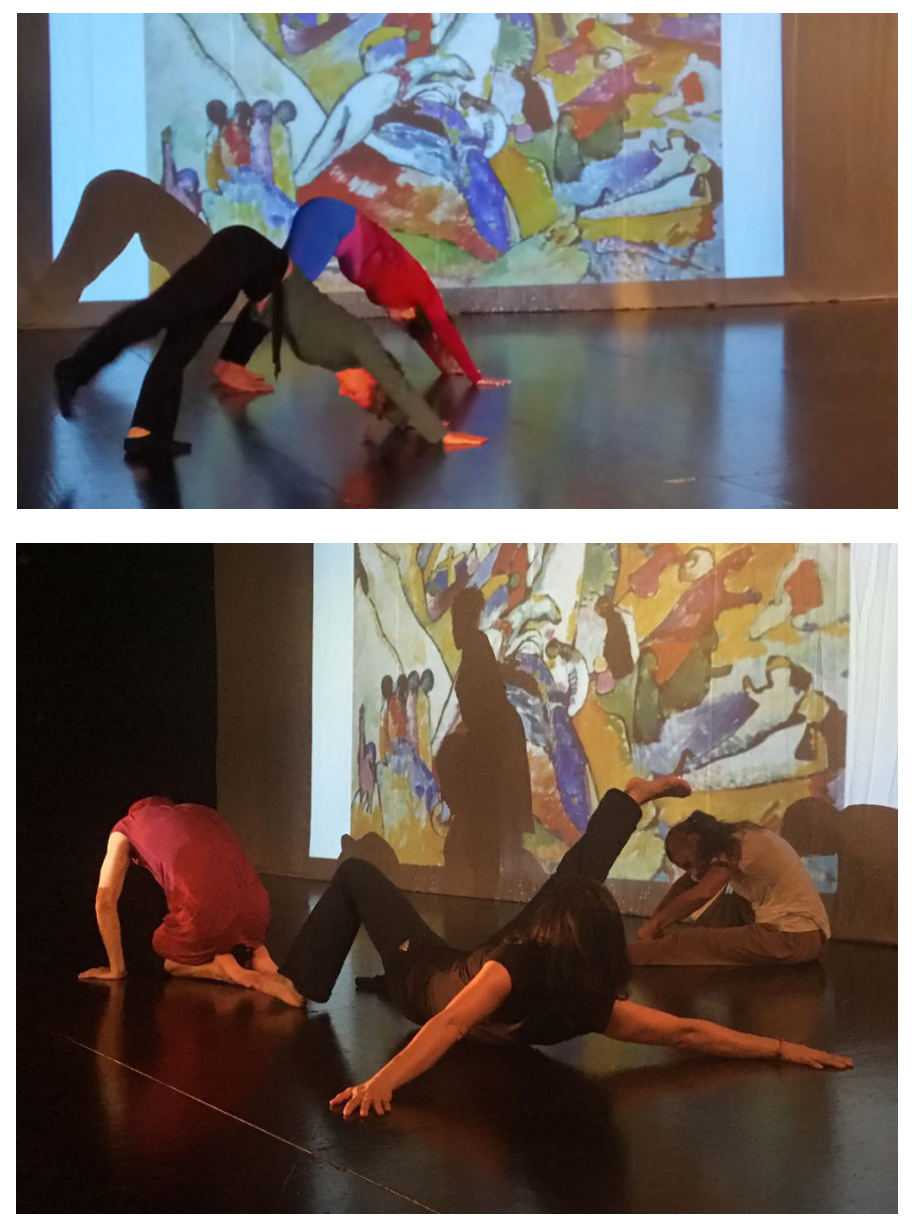

Fonte: Fotos de Sabrine Schultz.

Com a progressão das sessões de improvisação, fomos organizando e sequenciando os movimentos e os encontros em cena que ativavam imagens e afetos em nós e nos outros participantes, em uma construção dramatúrgica que era ao mesmo tempo pessoal (e individual de cada um - com sua partitura de movimentos) e também coletiva, envolvendo dinâmicas de todos os corpos presentes em cena. Dessa elaboração nasceu nossa obra Kandinsky, que, apesar de estruturada, continuava sendo improvisada, onde cada performer tinha mapa de afetos para guiar suas ações.

Se Kankinsky foi uma obra criada a partir da composição de afetos, empatia e cinestesias, sua dramaturgia, portanto, envolveria também a organização de tais processos. Em minhas pesquisas, 
venho trabalhando sobre a ideia de que o ato de pensar na e sobre a criação e, ao mesmo tempo, considerá-la em relação à composição da obra, sua recepção, seu significado, seu tema, seus porquês... é uma atitude dramatúrgica (SCIALOM, 2016). Aqui, dramaturgia é vista a partir do seu conceito expandido (SANCHEZ, 2011), que vem sendo revisado a partir da prática de diferentes linguagens artísticas, para além do texto teatral. Para articular o conceito, sigo o discurso que vem sendo desenvolvido no campo da dramaturgia na dança, o qual, nos últimos vinte anos, vem gerando uma área consistente de prática e pesquisa (SCIALOM, 2016).

Em dança, a atividade dramatúrgica pode atuar em diversos níveis e de diferentes formas, variando de acordo com o trabalho criativo, objetivo e o formato da obra (HANSEN; CALLISON, 2015). Scialom e Fabrini (2019) e Van Kerkhoven (2016) concordam que ela acontece no processo de criação e não antecede a ele como um texto criado de antemão. Dessa forma, durante o processo de criação, a dramaturgia opera como um pensamento sobre a organização cênica da obra (BEHRNDT, 2010). Nesse contexto, o autor desenvolve que a dramaturgia na dança se articula através da experiência prática, sendo assim materializada de forma única a cada processo criativo.

Por isso, ao se associar o "pensar em movimento" de Laban com o pensar dramatúrgico oriundo da dramaturgia na dança, considero Kandinsky não como uma proposta de improvisação, mas como uma proposta de experiência dramatúrgica. Observo que a diferença entre ambos se encontra no modo de agir e de acessar o conhecimento encarnado, visando uma criação coreográfica. Esta seria uma composição consciente e articulada, mesmo que emergindo no instante de sua realização, com total domínio sobre o movimento executado, distanciando a criação de uma prática de improvisação "comum"13.

13 Minha intenção não é a de opor dramaturgia e improvisação, e, sim, propor um olhar diferente, baseado no pensamento coreológico que acontece através do movimento e a experiência deste, para a ação que acontece em uma criação cuja forma dos movimentos executados não é fechada/fixa.
Para sustentar que Kandinsky é uma proposta de experiência dramatúrgica, sigo com o raciocínio de Synne Behrndt (2010), de que, quando os performers são os co-criadores da obra, eles são também responsáveis pelo conteúdo dramatúrgico dela e, assim, passam a formatar a dramaturgia do trabalho. Avançando com esta ideia, eu defendo que o pensar em movimento, enquanto uma organização das ações no espaço e tempo, concede ao performer um status de dramaturgo de seu próprio trabalho. Para tanto, a incorporação dos princípios da Coreologia de Rudolf Laban se tornam tanto o disparador da criação quanto o produto dela, enquanto a dramaturgia afetiva é o meio pelo qual ela é construída.

Figura 4 - Dançarinos durante ensaio-aberto de Kandinsky.

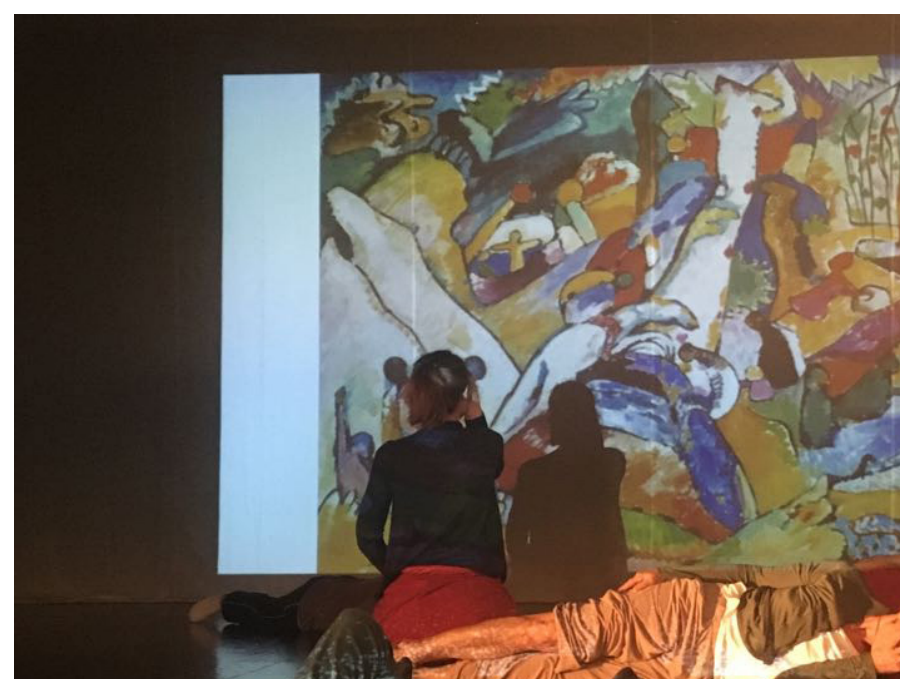

Fonte: Foto de Sabrine Schultz

\section{Conclusão}

Neste artigo, procurei vislumbrar como venho trabalhando com os EC na formação do performer-criador e como este, ao acionar seu conhecimento incorporado, torna-se também co-criador da dramaturgia da obra criada. Além de exemplificar como tenho avançado em um trabalho sobre as bases dos EC, com este artigo, busco trazer uma contribuição à pesquisa sobre dramaturgia na dança e à própria investigação sobre os desdobramentos possíveis do 
universo do movimento lançado por Laban na primeira metade do século XX e continuada por centenas de artistas-pesquisadores ao redor do mundo.

Acredito que seja justamente pelo fato de os EC serem diretamente ligados à produção e ao estudo da criação nas artes corporais, que eles facilitem o pensamento dramatúrgico do performer. Os EC - como um tipo de conhecimento a respeito de como o movimento acontece, opera e funciona artisticamente (e como venho propondo, afetivamente) - quando incorporado pelo artista-criador, transforma-se em uma possível plataforma para desenvolver um pensamento e uma atividade dramatúrgica no performer. A associação dos EC com uma pintura de Kandinsky, tendo a imagem como mapa afetivo, possibilitou a realização de um trabalho cuja improvisação foi se transformando em uma recriação, através de uma dramaturgia que opera num campo não-representacional, intensivo e cinestésico.

Nesse trabalho que venho desenvolvendo de prática como pesquisa laboratorial, busco incentivar o performer a se empoderar de seu ato criativo e, portanto, a ter autonomia em seus processos e atos de/em criação. Nesta perspectiva, ele se torna aquele que realiza decisões e faz o trabalho de pensar e agir ao mesmo tempo, configurando-se, assim, em uma prática alinhada com o próprio pensamento de Laban - no sentido metodológico, filosófico e prático. Acredito que esta visão tenha grande influência da diversidade de perspectivas labanianas que adquiri ao longo dos anos e no meu compromisso em olhar para a práxis modernista de Laban e seus princípios do movimento através de um corpo - do artista-pesquisador - contemporâneo, sempre em busca de manter este discurso acordado aos questionamentos de hoje.

\section{Referências}

BARDET, Marie. A filosofia da dança: um encontro entre dança e filosofia. São Paulo: Martins Fontes, 2016.
BEHRNDT, Synne K. Dance, Dramaturgy and Dramaturgical Thinking. Contemporary Theatre Review, v. 20, n. 2, p. 185-196, Maio 2010.

COHEN, Bonnie Bainbridge. Sentir, Perceber, e Agir: educação somática pelo método Body Mind Centering. São Paulo: Edições Sesc São Paulo, 2015.

DELEUZE, Gilles; GUATTARI, Felix. Mil Platôs. São Paulo, Brasil: Editora 34, 2017.

DÖRR, Evelyn. Rudolf Laban: the dancer of the crystal. Lanham, Md.: Scarecrow Press, 2008.

ELIAS, Marina. Improvisação como possibilidade de reinvenção da dança e do dançarino. Pós, Belo Horizonte, v. 5, n. 10, p. 173-182, nov. 2015.

FERNANDES, Ciane. et.al. A Arte do Movimento na Prática como Pesquisa. 2019, Natal, UFRN. Anais... Natal, UFRN: ABRACE, 2019. p. 1-24. Disponível em: https://www.publionline.iar.unicamp.br/index. php/abrace/article/view/3913. Acesso em: 01 abr. 2020.

HANSEN, Pil; CALLISON, Darcey. (Orgs.). Dance dramaturgy: modes of agency, awareness and engagement. Houndmills, Basingstoke Hampshire; New York, NY: Palgrave Macmillan, 2015.

LABAN, Rudolf Von. Choreutics. London: Macdonald \& Evans, 1966.

LABAN, Rudolf Von. Domínio do Movimento. Sao Paulo: Summus, 1978.

LONGSTAFF, Jeffrey Scott. Cognitive structures of kinesthetic space: reevaluating Rudolf Laban's choreutics in the context of spatial cognition and motor control. 1996. PhD Thesis - City University/Laban Centre, London, 1996. 
MALETIC, Vera. Body, space, expression: the development of Rudolf Laban's movement and dance concepts. Berlin; New York: Mouton de Gruyter, 1987.

MANNING, Erin. Politics of touch: sense, movement, sovereignty. Minneapolis: University of Minnesota Press, 2007.

MASSUMI, Brian. Politics of affect. Cambridge, UK ; Malden, MA: Polity, 2015.

MAUSS, Marcel. Techniques of the body. Economy and Society, v. 2, n. 1, p. 70-88, 1973.

MCCAW, Dick. (Org.). The Laban Sourcebook. New York: Routledge, 2011.

MOORE, Carol-Lynne. The harmonic structure of movement, music, and dance according to Rudolf Laban: an examination of his unpublished writings and drawings. Lewiston, N.Y.; Lampeter, UK.: Edwin Mellen Press, 2009.

PRESTON-DUNLOP, Valerie. Dance is a language isn't it? London: The Laban Centre for Movement and Dance, University of London, Goldsmith College, 1980.

The Nature of the Embodiment of Choreutic

Units in Contemporary Choreography. 1981. Tese Doutorado - University of London, Goldsmiths College, London, 1981.

. Laban, Schoenberg, Kandinsky. In: LOUPPE, L.; HOLMES, B.; CARRIER, P. (Org.). Traces of dance: drawings and notations of choregraphers. Paris:

Dis Voir, 1994.

PRESTON-DUNLOP, Valerie; SANCHEZ-COLBERG, Ana. Dance and the performative: a choreological perspective: Laban and beyond. Alton, Hampshire: Dance Books, 2010.
REYNOLDS, Dee. Kinesthetic empathy and the dance's body: From emotion to affect. In: REYNOLDS, D.; MATHEW, R. (Orgs.). Kinesthetic Empathy in Creative and Cultural Practices. London: Intellect/ University of Chicago Press, 2012. p. 121-138.

SANCHEZ, Jose Antonio. Dramaturgy in an expanded field. In: BELLISCO, M.; CIFUENTES, M. J. (Orgs.). Repensar la dramaturgia: errancia y transformación. Murcia: Centro Párraga: CENCDOC, 2011. p. 39-57.

SCIALOM, Melina. Dramaturgia na Dança: A Práxis de Rudolf Laban como Base para o Trabalho Dramaúrgico em Dança. Cadernos GIPE-CIT, v. 16, p. 145-166, 2016.

Quando ciência e arte se encontram no estúdio: prática de laboratório na pesquisa em artes cênicas. No prelo.

SCIALOM, Melina; FABRINI, Vêronica. Dramaturgia na dança: manipulação de energia no processo. $R e-$ vista Cena, v. 29, p. 2-13, set./dez 2019.

VAN KERKHOVEN, Marianne. O processo dramatúrgico. In: CALDAS, Paulo; GADELHA, Ernesto. (Orgs.). Dança e Dramaturgia[s]. Fortaleza: Nexus, 2016. p. 179-190.

Recebido: $14 / 06 / 2020$

Aceito: $31 / 07 / 2020$ Aprovado para publicação:17/11/2020 
Este é um artigo de acesso aberto distribuído sob os termos de uma Licença Crea- tive Commons Atribuição 4.0 Internacional. Disponível em: $<$ http://creative commons.org/licenses/by/4.0>.

This is an open-access article distributed under the terms of the Creative Commons Attribution License 4.0 International. Available at: <http://creative commons.org/licenses/by/4.0>.

Ce texte en libre accès est placé sous licence Creative Commons Attribution 4.0 International. Disponible sur: <http://creativecommons.org/licenses/by/4.0>. 